\section{Intussusception of the appendix}

Sir,

Intussusception of the appendix is a rare condition and about 160 cases have been reported since its first description. ${ }^{1}$ The diverse nature of the clinical profile of the intussusception of appendix is well known. ${ }^{2-5}$ The rarest amongst its various presentations is its asymptomatic occurrence which is usually discovered as an incidental finding during abdominal operation for another unrelated lesion. Only three cases have been documented previously. ${ }^{5-7}$ The following is the report of one such case recently managed by us.

A 16 year old girl presented with a history of biliary colic for the last 3 years. Six months previously, she had developed obstructive jaundice which abated with conservative treatment. The relevant investigations confirmed the diagnosis of cholelithiasis.

A cholecystectomy and choledocholithotomy was performed through a right paramedian incision. The appendix was sought to carry out an incidental appendicectomy. The caecum was mobile and could be easily delivered into the wound. The appendix could not be found at its expected location, but soon it was realized that it was totally invaginated into the caecum. The site of intussusception into the caecum was marked by a dimple. A narrow meso-appendix could be seen leading to it. The appendix could not be evaginated by squeezing it through the caecal wall. Therefore, as a first step, the mesoappendix was ligated and divided. Next, a semi-circular incision was made in the caecal wall around the base of the inverted appendix. The appendix was hooked out through this incision. Mucosa of the invaginated appendix was slightly oedematous and congested. The appendicectomy was accomplished by completing the circular incision all around the base of the appendix. The opening in the caecum was closed in two layers. Histopathology revealed the presence of chronic inflammation in the appendix. The postoperative period was uneventful and during this period the management centred on her biliary surgery.

It is interesting to note that in all the reported cases of asymptomatic intussusception of appendix, the patients were female and there was a co-existing gynaecological lesion in the pelvis. ${ }^{5-7}$ Our case had no such associated lesion. Although uncommon, awareness of the condition is important. While carrying out an incidental appendicectomy, intussusception of appendix may elude diagnosis unless the condition is known to the operator. Furthermore, to the unwary, the feel of intussuscepted appendix may suggest a tumour leading to unnecessary right hemicolectomy.?

Meera Relan
M.M. Das
S. Ray
Department of General Surgery,
Medical College \& Hospital,
88 College Street,
Calcutta, India.

\section{References}

1. Ellis, H. Appendix. In: Schwartz, S.I. \& Ellis, H. (eds) Maingot's Abdominal Operations, Vol. II, 8th edn. AppletonCentury-Crofts, Norwalk, Connecticut, 1985, pp. 1255-1288.

2. Fraser, K. Intussusception of the appendix. Br J Surg 1943, 31: 23-33.

3. Forshall, I. Intussusception of the vermiform appendix with a report of seven cases in children. Br J Surg 1953, 40: 305-312.

4. McSwain, B. Intussusception of the appendix. South Med J 1941, 34: 263-271.

5. Fink, V.H., Santos, A.L. \& Goldberg, S.L. Intussusception of the appendix. Am J Gastroenterol 1964, 42: 431-441.

6. Evans, A. Inversion of the vermiform appendix. Br J Surg 1922, 9: 565.

7. Schmidt, F.R. \& McCarthy, J.D. Intussusception of the appendix with endometriosis presenting as a caecal tumor. Arch Surg 1971, 103: 515-517. 